\title{
Late Diagnosis of Takayasu Disease in a 50-Year-Old African Black Woman with Repeated Episodes of Heart Failure: Seeing the Forest through the Trees-A Case Report
}

\author{
Djibril Marie BA ${ }^{1}$, Aminata Diack ${ }^{2}$, Alain Affangla1, Serigne Cheikh Tidiane Ndao ${ }^{3}$, \\ Madjiguene KA ${ }^{3}$, Khadidiatou DIA ${ }^{3}$, Mouhamed Cherif Mboup ${ }^{3}$, Mouhamed Leye ${ }^{1}$ \\ ${ }^{1}$ Unit of Research and Training in Medical Sciences, University of Thies, Thies, Senegal \\ ${ }^{2}$ Department of Radiology, Principal Hospital of Dakar, Dakar, Senegal \\ ${ }^{3}$ Department of Cardiology, Principal Hospital of Dakar, Dakar, Senegal \\ Email: gaby.11ba@yahoo.fr,diack.aminata@yahoo.fr,docalaf@gmail.com,sctndao@gmail.com, \\ madjigueneka@gmail.com,khady_dia@yahoo.fr,mcmboup@yahoo.fr, leyemohamed@gmail.com
}

How to cite this paper: BA, D.M., Diack, A., Affangla, A., Ndao, S.C.T., KA, M., DIA, K., Mboup, M.C. and Leye, M. (2020) Late Diagnosis of Takayasu Disease in a 50-Year-Old African Black Woman with Repeated Episodes of Heart Failure: Seeing the Forest through the Trees-A Case Report. World Journal of Cardiovascular Diseases, 10, 683-697.

https://doi.org/10.4236/wjcd.2020.1010066

Received: August 24, 2020

Accepted: October 19, 2020

Published: October 22, 2020

Copyright $\odot 2020$ by author(s) and Scientific Research Publishing Inc. This work is licensed under the Creative Commons Attribution International License (CC BY 4.0).

http://creativecommons.org/licenses/by/4.0/ (c) (i) Open Access

\begin{abstract}
Background: First described in 1908, TAK has now been recognized as a non-specific inflammatory disease of unknown etiology, predominantly affecting young females. Sometimes, it progresses into relatively rare and potentially fatal scenarios such heart failure. Case Presentation: Here, we present the case of a 50-year sub-saharan female suffering from acute heart failure related to TAK. Despite constitutional symptoms (fever, malaise, weight loss) and more characteristic features such claudication of lower extremities, carotydinia, and pulseless syndrome, diagnosis of TAK was delayed since main presentation was heart failure. Immunosuppressive and anticoagulant therapies have induced improvement in cardiac manifestations. Conclusion: Early diagnosis and proper treatment can protect the patient from dangerous complications such heart failure.
\end{abstract}

\section{Keywords}

Takayasu, Heart Failure, Corticotherapy, Pulseless Syndrome, Sub-Saharan, Black Female, Case Report

\section{Background}

Large vessel vasculitis (LVV), of which giant cell arteritis (GCA) and Takayasu arteritis (TAK) are the major subtypes, represents a group of diseases whose 
importance has been increasingly recognized over the years. Clinical manifestations for these diseases may vary from non-specific constitutional symptoms, such as fever, malaise and weight loss, to more characteristic features, resulting from stenosis/occlusion of the vascular territories involved.

Treatment of TAK consists of two strategies: immunosuppressive therapy for inflammation control and management of vascular diseases including control of blood pressure and surgical or interventional procedures [1].

First described in 1908, TAK is a rare chronic inflammatory disease of unknown etiology, predominantly affecting young females [2].

Its identical pathology is inflammatory infiltrates involving all arterial layers, including acute exudative inflammation and chronic granulomatous inflammation situated mainly in the media and adventitia while hyperplasia and neovascularization are found in the intimal layer [3].

Sometimes, it progresses into relatively rare and potentially fatal scenarios including acute visual loss, myocardial infarction, heart failure, cerebral thrombosis, and malignant hypertension.

Here, we present a case of a 50-year female suffering from acute heart failure related to TAK.

\section{Case Presentation}

A 50-year-old female resident in a border country (Guinea Conakry) was admitted in our hospital (Military Hospital of ouakam, Dakar, Senegal) for acute heart failure.

Her Medical history included hypertension nearly 5 years, managed with amlodipine (10 mg/day).

She started to develop intermittent claudication 4 years priorto admission. She was also reported to have low-gradefever, night sweats, myalagias, apparent weight loss, and carotidynia.

The heart failure first developed more than 3 years ago with sudden dyspnea and palpitation after what local hospital made the diagnosis of heart failure and prescribed diuretics and ACE in addition to amlodipine.

Although dyspnea resolved slowly, the claudication kept worsening gradually.

Over time, she develops more episodes of cardiac decompensation which become more and closer and more intense.

One month ago, her health deteriorated with a New York heart association (NYHA) class II dyspnea, and complained of decreased appetite, coughing, and pitting oedema of lower limbs and eyelids.

For a better exploration, she decides to come to our structure.

During her 5-day road trip, she omits to take her diuretic treatment and is admitted on arrival in a state of acute heart failure.

On admission, her height was $176 \mathrm{~cm}$ and weight was $89 \mathrm{~kg}$. Her body mass index (BMI) was $28.7 \mathrm{~kg} / \mathrm{m}^{2}$. Physical examination revealed a right arm blood pressure of 120/90 $\mathrm{mm} \mathrm{Hg}$, a left arm blood pressure of 100/68 $\mathrm{mm} \mathrm{Hg}$ and a 3/6 
systolic murmur over the right cervical region.

Her heart rate was $118 \mathrm{bpm}$ of regular rhythm. Jugular vein distensions, and pitting oedema of lower limbs were also noted. Coarse crackles were prominent in both lungs. Pulses of the bilateral radial arteries were not present. The bilateral femoral artery, popliteal artery and bilateral dorsalis pedis artery could be touched

Her discomforts improved after diuresis was initiated, and she was admitted to the Cardiac Unit in our hospital for further investigation.

The 12-lead electrocardiogram showed sinus rhythm, left atrial overloading, and left ventricle enlargement (Figure 1).

Blood tests revealed slight microcytic anemia, normal $\mathrm{C}$ reactive protein (CRP), an erythrocyte sedimentation rate (ESR) of $60 \mathrm{~mm} / \mathrm{h}$.

Cardiac ultrasound (Figure 2) revealed cardiac enlargement, and severe pulmonary arterial hypertension $(66.7 \mathrm{~mm} \mathrm{Hg})$. Left ventricular was dilated (diastolic diameter of $66.3 \mathrm{~mm}$ ) with reduced ejection fraction (LVEF) of $37.8 \%$. Tricuspid annular plane systolic excursion (TAPSE) was $9 \mathrm{~mm}$.

Since our patient met 3 out of criteria among those of the diagnosis of TA (symptoms of limb ischemia, physical findings of decreased pulses, and unsymmetrical blood pressure), we decided to perform a Doppler ultrasound which showed a complete occlusion of the common carotid artery and the subclavian on the left, and a thickening of the wall of the right subclavian artery.

Computed tomography angiography (Figure 3 ) revealed a diffuse thickening of the wall of the aorta more marked in the arch and the thoracic descending

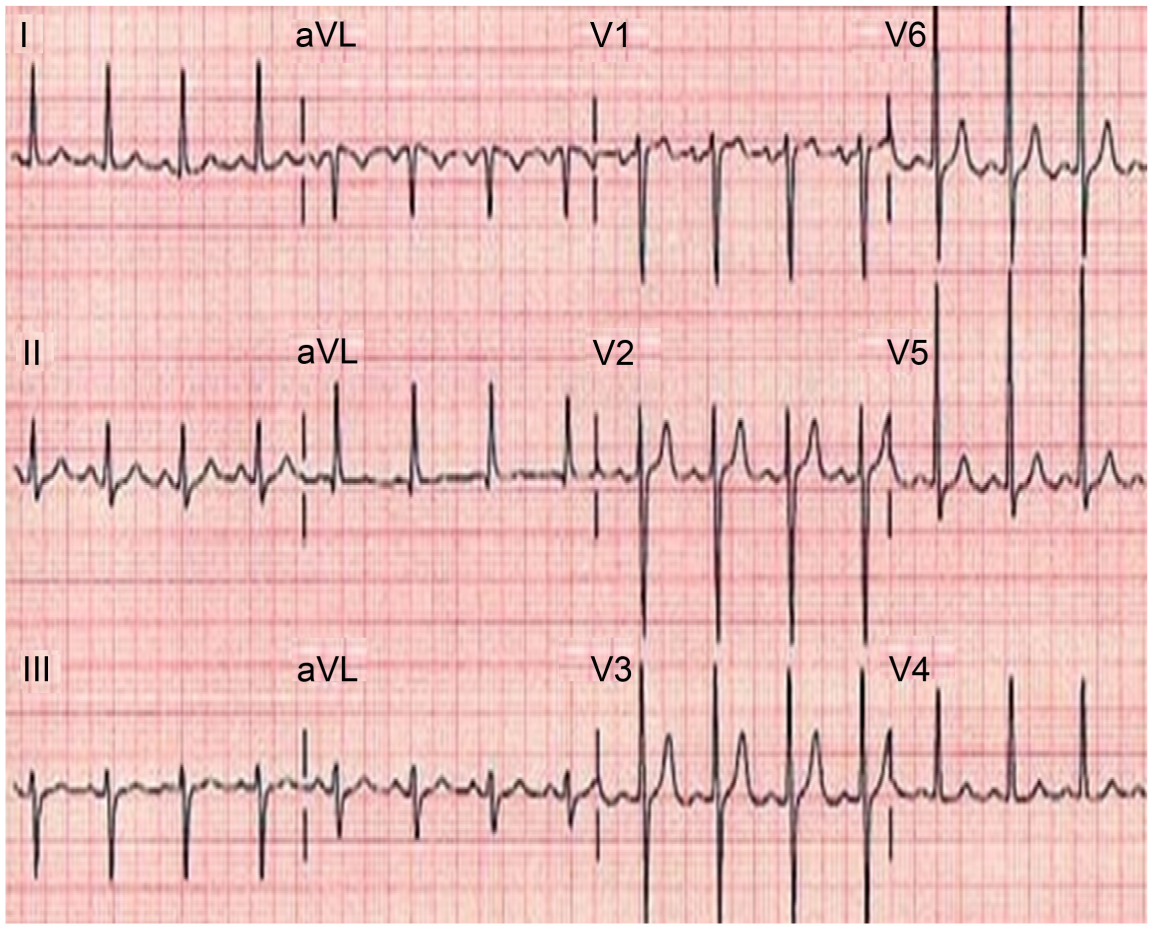

Figure 1. Twelve-lead electrocardiogram showing sinus rhythm, left atrial enlargement, and left ventricular enlargement. 


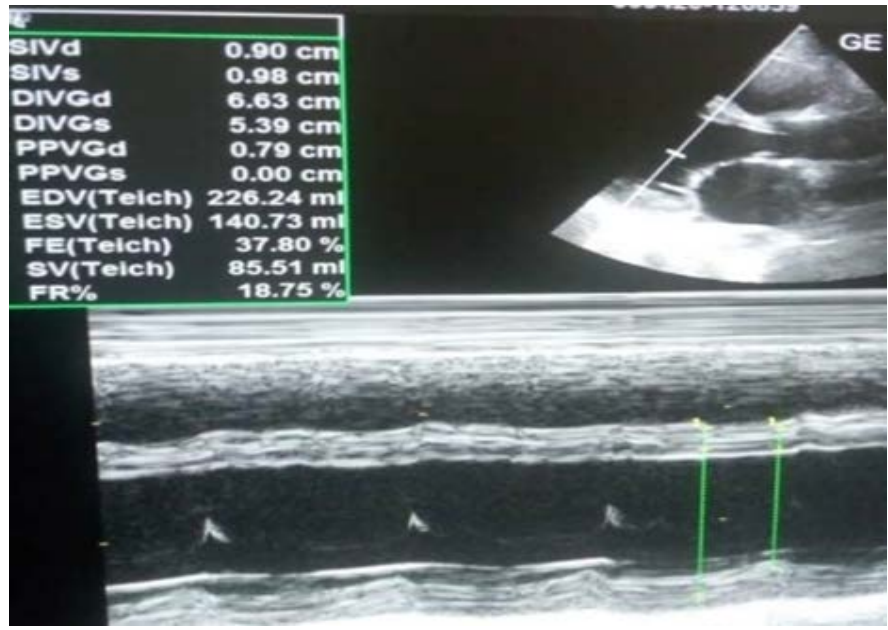

(a)

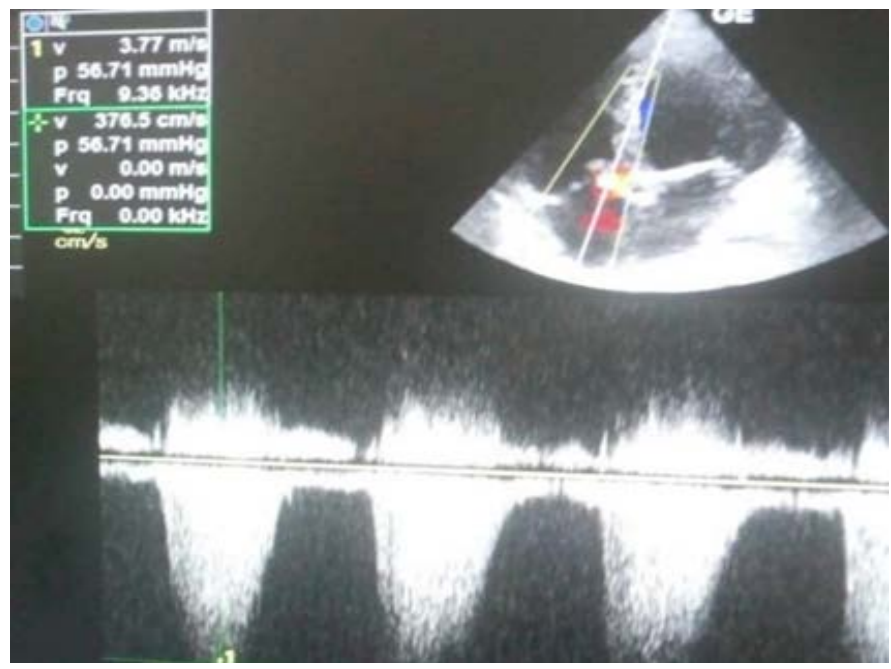

(b)

Figure 2. (a) Echocardiography showing dilated left ventricle with reduced ejection fraction (LVEF) of $37.8 \%$. (b) Severe pulmonary arterial hypertension.

aorta, reducing the aortic lumen between 3.8 and $7 \mathrm{~mm}$. The brachiocephalic trunk was stenosed with a $2.5 \mathrm{~mm}$ lumen with enhancement of the right carotid and the right subclavian artery.

There was an obstruction of the origin of the left common carotid artery and the left subclavian artery. The abdominal aorta and pulmonary arteries appeared normal. These angiographic findings classified our patient as type IIb.

Furosemide boluses, and oral ACE were administered to counter heart failure while low molecular weight heparin was injected subcutaneously for anticoagulation. Intravenous methylprednisolone $40 \mathrm{mg}$ daily and cyclophosphamide 400 mg weekly were initiated to treat TAK.

10 days later, her symptoms began to resolve and she was discharged after that we gradually transitioned from low molecular weight heparin to warfarin and switched from intravenous methylprednisolone to oral prednisone. 


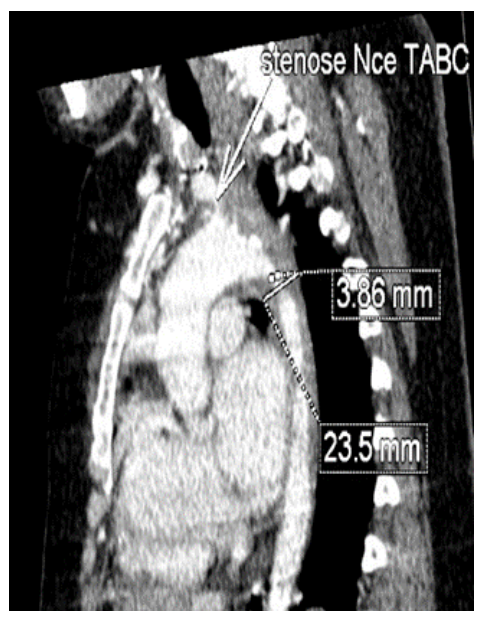

(a)

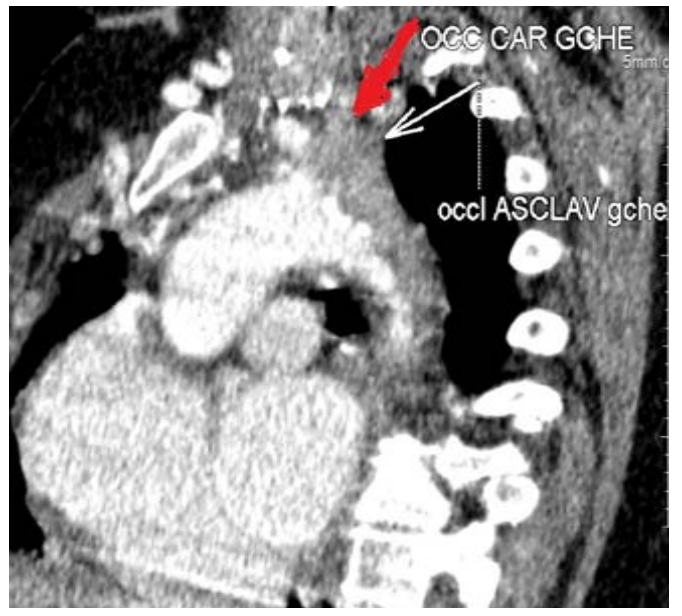

(b)

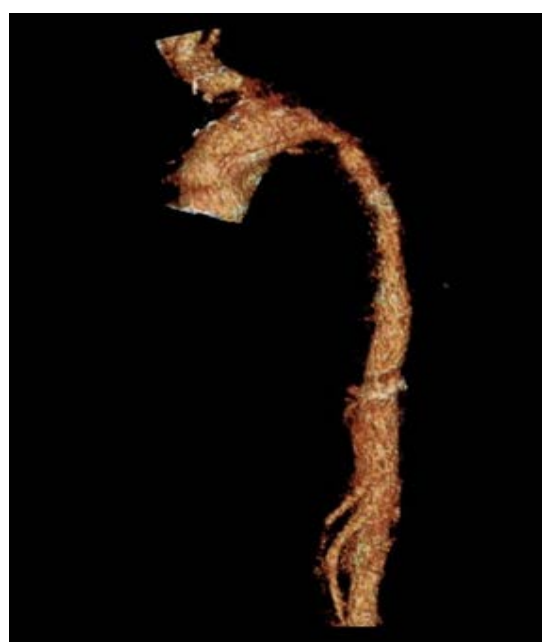

(c)

Figure 3. (a) Computed tomography angiography revealed a diffuse thickening of the wall of the aorta more marked in the arch and the thoracic descending aorta, reducing the aortic lumen between 3.8 and $7 \mathrm{~mm}$. The brachiocephalic trunk was stenosed (arrow). (b) obstruction of the origin of the left common carotid artery (red arrow) and the left subclavian (white arrow).

After five weeks, repeated echocardiography showed reduction of heart dimensions with LVEF $49.2 \%$, and a significant lowering in pulmonary pressure which returned to $39 \mathrm{~mm} \mathrm{Hg}$.

Clinically, she had no complaints and driven daily activities without difficulties.

\section{Discussion}

Systemic vasculitides are pathologically identified by the inflammation of blood vessel walls, and cause various organ disorders depending on the size of the affected blood vessels.

The first classification of vasculitis was proposed by Zeek in 1952 [4] [5].

In 1994, Jennette et al. published the results of the Chapel Hill Consensus 
Conference (CHCC) on the Nomenclature of Systemic Vasculitis [6]. They adopted names and definitions of vasculitides based on the size of the affected vessels, and categorized vasculitides into large-vessel vasculitis, medium-vessel vasculitis and small-vessel vasculitis.

Large-vessel vasculitis, including TAK and GCA, was defined as vasculitis affecting the aorta and its major branches more often than other vasculitides, whereas any size artery might be affected. It was concluded that these types of arteritis could not be distinguished by pathological findings, except for the difference in the age of onset [7].

Takayasu arteritis is a rare, large-vessel vasculitis of unknown etiology that most commonly affects women predominantly below 40 years of age.

The disease was first described by Professor Mikito Takayasu during the 12th Annual Meeting of the Japan Ophthalmology Society held in 1905 [8]. At the same meeting, Onishi and Kagoshima reported similar cases mentioning the patients also had abolished radial pulse, a finding overlooked by Takayasu [9].

The disease, subsequently known as "pulseless disease", "aortic arch syndrome", "occlusive thromboaortopathy", or "nonspecific arteritis", was named "Takayasu's arteritis" for the first time in 1942.

The disease has a worldwide distribution although it occurs more commonly in Asia [10]. It is now known that there are regional and ethnic differences in the clinical features of patients with vasculitis. Unfortunately, there is a paucity of data regarding these conditions in the developing world, including Africa, with most information arising from Western Caucasian populations. However, in recent years, there have been increasing reports which indicate that these conditions do occur in Africa, although hitherto infrequently reported [11].

In addition to symptoms resulting from the vascular territories involved, TAK can present with systemic symptoms including fever, weight loss and malaise. Unlike GCA (where a classical cranial pattern of symptoms can be described), in TAK there is no clear pattern of presentation. However, some differences in disease manifestations may occur according to age and gender.

Using an age between 12 and 35 years old plus the 1990 American College of Rheumatology (ACR) classification criteria for TAK as inclusion criteria, Mont'Alverne et al. [12] studied 55 patients with TAK (17 males and 38 females). Multivariate analysis showed that male gender was a risk factor for the occurrence of abdominal pain (OR 18.75; 95\% CI 2.89 to 121.54) and ascending aortic aneurysm (OR 9.51; 95\% CI 1.94 to 46.70). 9 There were no gender differences regarding the presence of constitutional symptoms, limb claudication, carotidynia, respiratory and articular manifestations, nor the presence of comorbidities.

Watanabe et al. [13] included 1372 patients (222 males and 1150 females) newly registered ( $<1$ year) in a nationwide Japanese registry and analysed data according to gender and age of disease onset ( $\leq 40$ vs $>40$ years). Gender analysis (although limited given the number of males compared with females) showed that, overall, the most common complications were hypertension and aortic 
valve regurgitation, with males having more complications than females (ischaemic heart disease, funduscopic alterations, aortic aneurysm and dissection, renal disorders, renal artery stenosis, and hypertension).

Most of the data from Africa has been published from Tunisia. Ghannouchi et al. [14] in a review of 37 Takayasu patients from 1985 to 2005 noted a mean age at presentation of 33.2 years (range 16 - 68 years) and found that $88.9 \%$ were female. Intermittent claudication was the most common presentation $(81.5 \%)$ and hypertension was noted in $40.7 \%$ of cases.

Mwipatayi et al. [15] also reviewed 272 cases from South Africa seen between the years 1952 and 2002. The mean age at presentation was 25 years (range 14 66 years) and $75 \%$ of patients were female. Interestingly, only $8 \%$ of the patients studied were Caucasian. Hypertension was the most common presentation (77\%) and was usually a consequence of renal artery stenosis or aortic coarctation.

Arnaud L et al. [16], in a Single-Center Retrospective Study of 82 Cases Comparing White, North African, and Black Patients, conducted in France found a median age at diagnosis of 39.3 years (range, $14-70$ years) in white patients, vs. 28.4 years (range, 12 - 54 years) in North African $(\mathrm{p}=0.02)$, and 28.0 years (range, $13-60$ years) in black patients $(\mathrm{p}=0.08)$. The proportion of patients who had onset of TAK after 40 years of age was significantly higher in white than in non-white patients $(40.0 \%$ vs. $18.6 \%, \mathrm{p}=0.03)$, suggesting that late-onset TAK may be a more specific feature of white patients.

Constitutional symptoms and ophthalmologic manifestations were the most frequent presenting features in white patients (13.9\% each). Claudication of extremities was most frequent in North African (27.8\%) and black (26.3\%) patients. [16]

Our patient presented with typical signs and symptoms of arterial blockages, but her most striking symptoms were total heart failure.

Prevalence of LV dysfunction in TAK has not been clarified. Observational studies have reported relatively high prevalence of LV dysfunction in TAK of $15 \%-50 \%$, [17] [18] [19] including non-hypertensive dilated cardiomyopathies in $4 \%-6 \%$. Since HF symptoms may often be masked in TAK patients, allowing underestimation of HF prevalence in TAK, further larger scale clinical studies are warranted for these patients. While multiple factors such as valvular regurgitation or coronary artery involvement are known to be related to LV dysfunction in TAK, vascular inflammation resulting in chronically elevated vascular resistance may be one of the underlying pathogenesis of LV dysfunction. Elevation of vascular resistance should be considered as a possible and reversible cause of LV dysfunction in TAK without myocarditis, coronary artery involvement, or valvular regurgitation.

Mwipatayi and Jeffery retrospectively analyzed 272 TAK patients and identified 90 individuals with cardiac failure, which accounted for $46 \%$ of all-cause mortality (29 out of 57) [15]. Main causes of heart failure in TAK patients were increased afterload due to renovascular hypertension and aortic regurgitation. 
Myocardial ischaemia induced by myocarditis, accelerated atherosclerosis, or severe pulmonary hypertension were also noted [18].

For our patient, echocardiographic findings make us suspect myocarditis.

Occurring not uncommonly in TAK patients, myocarditis tends to occur early in disease course and appears to correlate with the disease's activity. In 1988 and 1991, Talwar et al. separately performed serial endomyocardial biopsies in TAK patients and myocarditis were identified in 8 out of 18 and 24 out of 54 patients [18].

The pathophysiology was believed to be direct immune cytotoxicity towards the myocardium.

The aorta can be involved along its entire length, and although any of its branches can be diseased, the most commonly affected are the subclavian and common carotid arteries [20] [21]. Although the most frequent pattern of disease varies geographically [21] [22], stenotic lesions found in $>90 \%$ of patients predominate, whereas aneurysms are reported in approximately 25\% [15] [23] [24] [25] [26] Pulmonary arteries are involved in up to 50\% of patients [27] [28], and it is important to look specifically for evidence of aortic valve regurgitation and coronary arteritis.

The distribution of vascular affection of the disease also varies by region, with cervical and thoracic arterial lesions being more common in Japan and South America contrary to abdominal lesions in other Asian countries [29]. The coronary ostia, pulmonary arteries and renal arteries may also be involved.

Ghannouchi et al. in a review of 37 Takayasu patients from 1985 to 2005 noted that The subclavian artery was the most frequently affected site in this cohort [14]. Another retrospective study done in southern Tunisia by Kechaou et al. between 1996 and 2006 collected and analyzed 29 patients ( 25 femalesand 4 males). Ninety-three percent of vessels affected included the aortic arch and its branches, while only $24 \%$ involved the renal arteries and $21 \%$ the abdominal aorta [30]. A retrospective study by Elasri et al. among 47 Moroccan patients reviewed between the years 1988 and 1999 reported that involvement of the aortic arch and its branches was more frequent than the involvement of the abdominal aorta and its branches [31] as the case in our patient.

The diagnosis of TAK requires at least three of the American College of Rheumatology criteria (Table 1) 7 to be present. This criterion is said to have a

Table 1. 1990 american college of rheumatology criteria of the diagnosis of TAK.

\begin{tabular}{cc}
\hline 1 & Age at onset $\leq 40$ years \\
2 & Limb claudication \\
3 & Diminished brachial pulse \\
4 & Difference of $>10 \mathrm{~mm} \mathrm{Hg}$ systolic pressure between arms \\
5 & Bruit over the subclavian artery or aorta \\
6 & Abnormalangiogram \\
& For Diagnosis $\geq 3$ criteria should be present (sensitivity: $90.5 \%$, specificity: $97.8 \%)$ \\
\hline
\end{tabular}


sensitivity of $91 \%$ and specificity of up to $98 \%$. Our patient fulfilled all criteria except age at the onset of disease.

Takayasu arteritis is usually diagnosed in young individuals in their second and third decade of life and affects females in most cases (82.9\% - 97.0\%) [32] [33] [34]. Generally, TAK has been defined arbitrarily as a disease with onset prior to the age of 40 . An age $<40$ years was selected as a mandatory criterion in the original Ishikawa diagnostic criteria and is a non-mandatory criterion in the 1990 American College of Rheumatology (ACR) classification criteria. However, occurrence of TAK in patients older than 40 years is not rare. Recent studies conducted in different populations indicate that the proportion of patients aged over 40 years at disease onset varies from $9 \%$ to $32 \%$ [16] [33] [35] and at the time of diagnosis varies from $15 \%$ to $71 \%$ [10] [36] [37].

Ideally, the diagnosis of Takayasu arteritis should be made early in the pre-stenotic phase. In theory, this would allow initiation of treatment to suppress inflammation and prevent vascular injury.

A delay in diagnosis of many months or years is typical, even in patients in whom diminished or absent pulsation has been recorded [23].

Although the reasons for the delay are multifactorial, important additional factors include the lack of easy access to biopsy material and, to some extent, the limitations of current diagnostic criteria. The American College of rheumatology and Ishikawa criteria [38] favor the detection of established stenotic disease and have not yet been revised in response to the increasing sensitivity of noninvasive imaging for the detection of pre-stenotic disease. Moreover, the likelihood of early diagnosis is not improved by the variable nature of disease presentation, and the lack of constitutional symptoms in $30 \%-50 \%$ of patients at presentation [25] [26].

Imaging of arteries is very useful in diagnosing TAK and for patient follow-up. Conventional angiography was formerly the gold standard, and currently it is often replaced with computerized tomography (CT) or magnetic resonance (MR) angiography in routine practice.

Imaging methods allow distinguishing different types of TAK, depending on location of vascular lesions. The disease can be classified into 5 types (Figure 4).

To date, no established biological marker specific to the diagnosis of patients with TAK has been reported. Patients with TAK often present increased inflammation markers, including C-reactive protein (CRP) and erythrocyte sedimentation rate (ESR). However, systemic inflammatory response does not always show a positive correlation with inflammatory activity in the vessel wall. Therefore TAK may be active without increasing CRP or ESR, and vice versa.

For the treatment and outcomes, early implementation of immunosuppressive therapy seemed to be responsive.

Glucocorticoids remain the basic and the most effective first line TAK treatment. Initially, in the presence of active TAK disease, the treatment of choice is high-dose $(0.8-1 \mathrm{mg} / \mathrm{kg} /$ day, p.o.) prednisolone or an equivalent. Generally, two thirds of the total daily dose is given early in the morning and the rest of the 


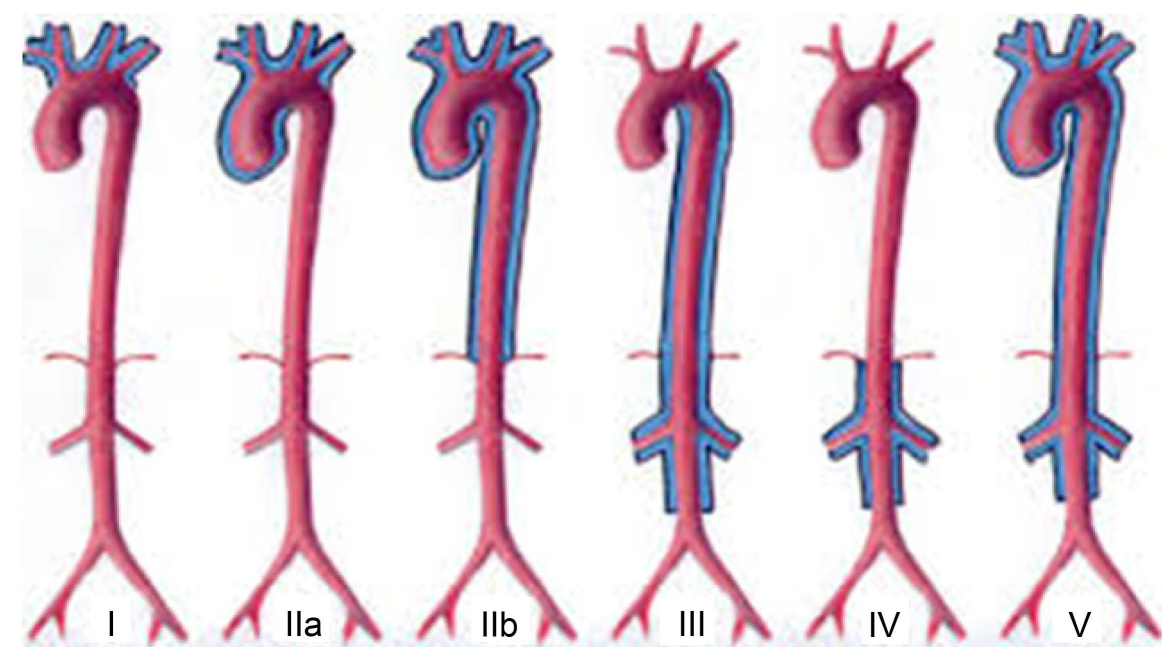

Figure 4. Type I: type that affects blood vessels of aortic arch. Type IIa: affects ascending aorta, aortic arch and its branches. Type IIb: affects ascending aorta, aortic arch and its branches. Thoracic descending aorta. Type III: affects thoracic descending aorta and abdominal aorta and/or renal arteries. Type IV: affects abdominal aorta and/or renal arteries. Type V: combined features of types IIb and IV.

dose in the evening after meals. This treatment is maintained until symptoms and laboratory evidence (ESR, CRP) of inflammation normalize (usually 4 - 6 weeks, sometimes up 12 weeks). With control of inflammation, corticosteroid therapy can be tapered to (typically about 10 percent every week) a maintenance dose of $0.1-0.2 \mathrm{mg} / \mathrm{kg} /$ day ( $\leq 15 \mathrm{mg} /$ day). For the prevention of relapse, treatment is usually continued for $1-2$ years. The response to high dose prednisolone is generally favorable, but relapses may occur while gradually tapering the dose and adverse effects of long-term treatment can cause problems. Therefore sometimes physicians start treatment from conventional immunosuppressant agents together with initial glucocorticosteroid treatment or while tapering thesteroid dose [39] [40] [41].

Talwar et al. chose combined therapy of prednisolone and cyclophosphamide over 12 weeks, and improvements were evident not only in clinical and haemodynamic states but also myocardial morphology [18]. Takeda used steroid therapy for 2 months, and the patient's symptoms were markedly alleviated, and his cardiac function and morphology greatly improved [42]. For our patient, we initiated the treatment regimen of corticosteroids and cyclophosphamide, and her symptoms resolved after 5 weeks, together with the heart's structural and functional improvement.

In cases where immunosuppressive drugs are insufficient, biological therapy should be introduced. Observational studies provide evidence that biological agents such as anti-tumor necrosis factor (anti-TNF), rituximab and tocilizumab are beneficial and could be used effectively in refractory TAK [43]. Biological agents are not recommended as monotherapy (i.e. without GC) nor as first line, add-on therapy to GC in newly-diagnosed TAK patients [44].

In chronic stages of TAK, patients with ischemic symptoms need to be treated 
with endovascular revascularization or vascular surgery (such as balloon angioplasty or stent). Procedures should be undertaken only after the suppression of inflammation in the affected arteries. Surgical procedures carry risk of restenosis or occlusion and success rate depends upon the location and stage of stenosis of blood vessel [45].

The presence of major complications, progressive disease course and older age are unfavourable prognostic indicators, as Ishikawa and colleagues demonstrated in a series of prospective observational studies.

In this study, peak death rates occurred early, in the first year after diagnosis $(\mathrm{n}=10 / 16)$ and late in the disease course, $>10$ years after diagnosis $(\mathrm{n}=5 / 16)$. Major causes of death were congestive heart failure, acute myocardial infarction, cerebrovascular accidents and postoperative complications [24]. These results are corroborated by other authors reporting that overall survival decreases in the first 5 years of disease, and event-free survival rates decrease progressively along the years, even more for patients with severe forms of disease (severe or multiple complications) or progressive course and carotidynia [35] [46].

In the study conducted by Mwipatayi, the most common cause of death was cardiac failure [15].

\section{Conclusions}

TAK belongs to rare, idiopathic diseases of the immune system affecting the aorta and its branches. Various presentations of TAK have been recorded, including cardiac involvement.

Despite the disease being recognized for more than 100 years, the outlook for patients with TAK remains relatively poor in Africa.

This is the first case of TAK with heart failure reported in black African. Clinical practitioners should be aware of this disease.

Early diagnosis and proper treatment can protect the patient from dangerous complications such heart failure.

\section{Conflicts of Interest}

The authors declare no conflicts of interest regarding the publication of this paper.

\section{References}

[1] Isobe, M. (2013) Takayasu Arteritis Revisited: Current Diagnosis and Treatment. International Journal of Cardiology, 168, 3-10. https://doi.org/10.1016/j.ijcard.2013.01.022

[2] Silva de Souza, A.W. and de Carvalho, J.F. (2014) Diagnostic and Classification Criteria of Takayasu Arteritis. Journal of Autoimmunity, 48-49, 79-83. https://doi.org/10.1016/j.jaut.2014.01.012

[3] Mason, J.C. (2010) Takayasu Arteritis Advances in Diagnosis and Management. Nature Reviews Rheumatology, 6, 406-415.

https://doi.org/10.1038/nrrheum.2010.82 
[4] Zeek, P.M. (1952) Periarteritis Nodosa; a Critical Review. American Journal of Clinical Pathology, 22, 777-790. https://doi.org/10.1093/ajcp/22.8.777

[5] Zeek, P.M. (1953) Periarteritis Nodosa and Other Forms of Necrotizing Angiitis. The New England Journal of Medicine, 248, 764-772.

https://doi.org/10.1056/NEJM195304302481805

[6] Jennette, J.C., Falk, R.J., Andrassy, K., et al. (1994) Nomenclature of Systemic Vasculitides. Proposal of an International Consensus Conference. Arthritis \& Rheumatology, 37, 187-192. https://doi.org/10.1002/art.1780370206

[7] Katsuyama, T., Sada, K.-E. and Makino, H. (2014) Current Concept and Epidemiology of Systemic Vasculitides. Allergology International, 63, 505-513. https://doi.org/10.2332/allergolint.14-RAI-0778

[8] Terao, C. (2014) History of Takayasu Arteritis and Dr. Mikito Takayasu. International Journal of Rheumatic Diseases, 17, 931-935. https://doi.org/10.1111/1756-185X.12576

[9] Numano, F. (2002) The Story of Takayasu Arteritis. Rheumatology (Oxford), 41, 103-106. https://doi.org/10.1093/rheumatology/41.1.103

[10] Watts, R., Al-Taiar, A., Mooney, J., Scott, D. and Macgregor, A. (2009) Theepidemiology of Takayasu Arteritis in the UK. Rheumatology (Oxford), 48, 1008-1011. https://doi.org/10.1093/rheumatology/kep153

[11] Genga, E., Oyoo, O. and Adebajo, A. (2018) Vasculitis in Africa. Current Rheumatology Reports, 20, 4. https://doi.org/10.1007/s11926-018-0711-y

[12] Mont'Alverne, A.R.S., Paula, L.E. and Shinjo, S.K. (2013) Features of the Onset of Takayasu's Arteritis According to Gender. Arquivos Brasileiros de Cardiologia, 101, 359-363. https://doi.org/10.5935/abc.20130180

[13] Watanabe, Y., Miyata, T. and Tanemoto, K. (2015) Current Clinical Features of New Patients with Takayasu Arteritis Observed from Cross Country Research in Japan: Age and Sex Specificity. Circulation, 132, 1701-1709. https://doi.org/10.1161/CIRCULATIONAHA.114.012547

[14] Ghannouchi, J.N., Khalifa, M., Rezgui, A., Alaoua, A., Ben, J.E., Braham, A., et al. (2010) Takayasudisease in Central Tunisia, 27 Cases. Journal des Maladies Vasculaires, 35, 4-11. https://doi.org/10.1016/j.jmv.2009.09.002

[15] Mwipatayi, B.P., Jeffery, P.C., Beningfield, S.J., Matley, P.J., Naidoo, N.G., Kalla, A.A., et al. (2005) Takayasu Arteritis: Clinical Features and Management: Report of 272 Cases. ANZ Journal of Surgery, 75, 110-117. https://doi.org/10.1111/j.1445-2197.2005.03312.x

[16] Arnaud, L., Haroche, J., Limal, N., et al. (2010) Takayasu Arteritis in France: A Single-Center Retrospective Study of 82 Cases Comparing White, North African, and Black Patients. Medicine, 89, 1-17. https://doi.org/10.1097/MD.0b013e3181cba0a3

[17] Panja, M., Kar, A.K., Dutta, A.L., Chhetri, M., Kumar, S. and Panja, S. (1992) Cardiac Involvement in Non-Specific Aorto-Arteritis. International Journal of Cardiology, 34, 289-295. https://doi.org/10.1016/0167-5273(92)90027-Z

[18] Talwar, K.K., Kumar, K., Chopra, P., Sharma, S., Shrivastava, S., Wasir, H.S., Rajani, M. and Tandon, R. (1991) Cardiac Involvement in Nonspecific Aortoarteritis (Takayasu's Arteritis). American Heart Journal, 122, 1666-1670. https://doi.org/10.1016/0002-8703(91)90285-P

[19] Lee, G.Y., Jang, S.Y., Ko, S.M., Kim, E.K., Lee, S.H., Han, H., Choi, S.H., Kim, Y.W., Choe, Y.H. and Kim, D.K. (2012) Cardiovascular Manifestations of Takayasu Arte- 
ritis and Their Relationship to the Disease Activity: Analysis of 204 Korean Patients at a Single Center. International Journal of Cardiology, 159, 14-20. https://doi.org/10.1016/j.ijcard.2011.01.094

[20] Jain, S., Kumari, S., Ganguly, N.K. and Sharma, B.K. (1996) Current Status of Takayasu Arteritis in India. International Journal of Cardiology, 54, S111-S116. https://doi.org/10.1016/S0167-5273(96)88780-8

[21] Subramanyan, R., Joy, J. and Balakrishnan, K.G. (1989) Natural History of Aortoarteritis (Takayasu's Disease). Circulation, 80, 429-437. https://doi.org/10.1161/01.CIR.80.3.429

[22] Sharma, B.K., Sagar, S., Singh, A.P. and Suri, S. (1992) Takayasu Arteritis in India. Heart Vessels, 7, 37-43. https://doi.org/10.1007/BF01744542

[23] Kerr, G.S., et al. (1994) Takayasu Arteritis. Annals of Internal Medicine, 120, 919-929. https://doi.org/10.7326/0003-4819-120-11-199406010-00004

[24] Ishikawa, K. and Maetani, S. (1994) Long-Term Outcome for 120 Japanese Patients with Takayasu's Disease. Clinical and Statistical Analyses of Related Prognostic Factors. Circulation, 90, 1855-1860. https://doi.org/10.1161/01.CIR.90.4.1855

[25] Maksimowicz-McKinnon, K., Clark, T.M. and Hoffman, G.S. (2007) Limitations of Therapy and a Guarded Prognosis in an American Cohort of Takayasu Arteritis Patients. Arthritis \& Rheumatology, 56, 1000-1009.

https://doi.org/10.1002/art.22404

[26] Park, M.C., Lee, S.W., Park, Y.B., Chung, N.S. and Lee, S.K. (2005) Clinical Characteristics and Outcomes of Takayasu's Arteritis: Analysis of 108 Patients Using Standardized Criteria for Diagnosis, Activity Assessment, and Angiographic Classification. Scandinavian Journal of Rheumatology, 34, 284-292. https://doi.org/10.1080/03009740510026526

[27] Lupi, E., Sánchez, G., Horwitz, S. and Gutierrez, E. (1975) Pulmonary Artery Involvement in Takayasu's Arteritis. Chest, 67, 69-74. https://doi.org/10.1378/chest.67.1.69

[28] Yamada, I., et al. (1992) Pulmonary Artery Disease in Takayasu's Arteritis: Angiographic Findings. American Journal of Roentgenology, 159, 263-269.

https://doi.org/10.2214/ajr.159.2.1352939

[29] JCS Joint Working Group (2011) Guideline for Management of Vasculitis Syndrome (JCS 2008). Japanese Circulation Society. Circulation Journal, 75, 474-503. https://doi.org/10.1253/circj.CJ-88-0007

[30] Kechaou, M., Frigui, M., Ben Hmida, M. and Bahloul, Z. (2009) Takayasu Arteritis in Southern Tunisia a Study of 29 Patients. La Presse Médicale, 38, 1410-1414. https://doi.org/10.1016/j.lpm.2008.10.023

[31] Elasri, A., Tazi-Mezalek, Z., Aouni, M., Adnaoui, M., Mohattane, A., Bensaid, Y., et al. (2002) Takayasu's Disease in Morocco. Report of 47 Cases. Revue de Médecine Interne, 23, 9-20. https://doi.org/10.1016/S0248-8663(01)00510-0

[32] de Souza, A.W. and de Carvalho, J.F. (2014) Diagnostic and Classification Criteria of Takayasu Arteritis. Journal of Autoimmunity, 48-49, 79-83. https://doi.org/10.1016/j.jaut.2014.01.012

[33] Gudbrandsson, B., Molberg, Ø., Garen, T. and Palm, Ø. (2017) Prevalence, Incidence, and Disease Characteristics of Takayasu Arteritis by Ethnic Background: Data from a Large, Population-Based Cohort Resident in Southern Norway. Arthritis Care \& Research (Hoboken), 69, 278-285. https://doi.org/10.1002/acr.22931 
[34] Richards, B.L., March, L. and Gabriel, S.E. (2010) Epidemiology of Large Vessel Vasculidities. Best Practice \& Research: Clinical Rheumatology, 24, 871-883. https://doi.org/10.1016/j.berh.2010.10.008

[35] Soto, M.E., Espinola, N., Flores-Suarez, L.F. and Reyes, P.A. (2008) Takayasu Arteritis: Clinical Features in 110 Mexican Mestizo Patients and Cardiovascular Impact on Survival and Prognosis. Clinical and Experimental Rheumatology, 26, S9-S15.

[36] Dreyer, L., Faurschou, M. and Baslund, B. (2011) A Population-Based Study of Takayasu's Arteritis in Eastern Denmark. Clinical and Experimental Rheumatology, 29, S40-S42.

[37] Mohammad, A.J. and Mandl, T. (2015) Takayasu Arteritis in Southern Sweden. The Journal of Rheumatology, 42, 853-858. https://doi.org/10.3899/jrheum.140843

[38] Ishikawa, K. (1998) Diagnostic Approach and Proposed Criteria for the Clinical Diagnosis of Takayasu's Arteriopathy. Journal of the American College of Cardiology, 12, 964-972. https://doi.org/10.1016/0735-1097(88)90462-7

[39] Aydin, S.Z., Direskeneli, H., Sreih, A., Alibaz-Oner, F., Gul, A., Kamali, S., et al. (2015) Update on Outcome Measure Development for Large Vessel Vasculitis: Report from OMERACT 12. The Journal of Rheumatology, 42, 2465-2469. https://doi.org/10.3899/jrheum.141144

[40] Kötter, I., Henes, J.C., Wagner, A.D., Loock, J. and Gross, W.L. (2012) Does glucocorticosteroid-Resistant Large-Vessel Vasculitis (Giant Cell Arteritis and Takayasu Arteritis) Exist and How Can Remission Be Achieved? A Critical Review of the Literature. Clinical and Experimental Rheumatology, 30, S114-S129.

[41] Sun, Y., Ma, L., Ma, L., Kong, X., Chen, H., Lv, P., et al. (2017) Cyclophosphamide Could Be a Better Choice than Methotrexate as Induction Treatment for Patients with More Severe Takayasu's Arteritis. Rheumatology International, 37, 2019-2026. https://doi.org/10.1007/s00296-017-3847-6

[42] Takeda, N. (2005) Takayasu Myocarditis Mediated by Cytotoxic T Lymphocytes. Internal Medicine, 44, 256-260. https://doi.org/10.2169/internalmedicine.44.256

[43] Mekinian, A., Comarmond, C., Resche-Rigon, M., Mirault, T., Kahn, J.E., Lambert, M., et al. (2015) Efficacy of Biological-Targeted Treatments in Takayasu Arteritis: Multicenter, Retrospective Study of 49 Patients. Circulation, 132, 1693-1700. https://doi.org/10.1161/CIRCULATIONAHA.114.014321

[44] Muratore, F., Pipitone, N. and Salvarani, C. (2017) Standard and Biological Treatment in Large Vessel Vasculitis: Guidelines and Current Approaches. Expert Review of Clinical Immunology, 13, 345-360. https://doi.org/10.1080/1744666X.2017.1285699

[45] Keser, G., Direskeneli, H. and Aksu, K. (2014) Management of Takayasu Arteritis: A Systematic Review. Rheumatology (Oxford), 53, 793-801. https://doi.org/10.1093/rheumatology/ket320

[46] Yang, L., Zhang, H., Jiang, X., et al. (2014) Clinical Manifestations and Long-Term Outcome for Patients with Takayasu Arteritis in China. The Journal of Rheumatology, 41, 2439-2446. https://doi.org/10.3899/jrheum.140664 


\section{Abbreviations}

LVV: Large vessel vasculitis

GCA: giant cell arteritis

TAK: Takayasu arteritis

ACE: angiotensin-converting enzyme

NYHA: New York heart association

BMI: body Mass Index

CRP: $C$ reactive protein

ESR: Erythrocyte sedimentation rate

LVFE: left ventricular fraction ejection

TAPSE: Tricuspid annular plane systolic excursion

CHCC: Chapel Hill Consensus Conference

LV: Left Ventricle

ACR: American College of Rheumatology

CT: computerized tomography

MR: magnetic resonance

Anti-TNF: anti-tumor necrosis factor 